\title{
XXVI. Notice respecting a volcanic appearance in the moon, in a letter addressed to the president
}

\section{Captain Henry Kater F.R.S.}

To cite this article: Captain Henry Kater F.R.S. (1821) XXVI. Notice respecting a volcanic appearance in the moon, in a letter addressed to the president, Philosophical Magazine Series 1, 58:280, 113-114, DOI: $10.1080 / 14786442108652582$

To link to this article: http://dx.doi.org/10.1080/14786442108652582

里 Published online: 29 Jul 2009.

Submit your article to this journal

Џ Article views: 2 


\section{[ 113 ]}

XXVI. Notice respecting a Volcanic Appearance in the Moon, in a Letter addressed to the President. By Captain Hrnqy KATER, F.R.S.*

London, Feb. 8, 1821. Dear Sir,- I may perhaps be interesting to the Royal Society to be informed, that on Sunday evening, the 4 th instant, I observed a luminous spot in the dark part of the moon, which I was inclined to ascribe to the eruption of a volcano.

The telescope used was an excellent Newtonian of $6 \frac{1}{4}$ inches aperture, with a power of 74 . The moon was exactly two days old, and the evening so clear, that I was able to discern the general outlines in the dark part of her disk. Her western azimuth was about $70^{\circ}$, and her altitude about 10 degrees.

In this position at 6 hours 30 minutes, the volcano was situated (estimating by the eye) as in the accompanying sketch [distant from the northern limb of the moon about one-tenth of her diameter]. Its appearance was that of a small nebula subtending an angle of about three or four seconds.

Its brightness was very variable; a luminous point, like a small star of the 6 th or 7 th magnitude, would suddenly appear in its centre, and as suddenly disappear, and these changes would sometimes take place in the course of a few seconds.

On the evening of the 5 th, having an engagement which prevented my observing it myself, I arranged the telescope for two friends, who remarked the same phænomena as the night before, but in an inferior degree, partly perhaps in consequence of the evening not being so favourable.

On the 6 th, I again observed it; it had certainly hecome more faint, and the star-like appearance less frequent. I could see it very distinctly with a power of 40 . As the moon approached the horizon, it was visible only at intervals when the star-like appearance took place. On the same evening I had the pleasure of showing it to Mr. Henry Browne, F.R.S.

I regret that $I$ had no micrometer adapted to my telescope ; but I have reason to believe the distance of the volcano from the edge of the moon was about one-tenth of her diameter, and the angle it formed this evening with a line joining the cusps was about $50^{\circ}$.

I remarked near the edge of the moon, a well known dark spot, from which the volcano was distant, as nearly as I could estimate, three times its distance from the edge of the moon.

In a map of the moon published by Dr. Kitchener (and which is the best small map with which $I$ am acquainted), there is a mountain sufficiently near the situation of the volcano, to anthorize the supposition that they may be identical.

* From the Transactions of the Royal Society for 1821, Part I. Vol, 58, No. 280. Aug. 1821. 
On the 7 th, I could still see the volcano, and the occasional star-like appearance; but I do not think it was sufficiently perceptible to have been discovered by a person ignorant of its precise situation. I am inclined however to think, that the diffculty of seeing it is rather to be attributed to the increased light of the moon, than to the diminished action of the volcano.

I have the honour to be, dear sir, \&ic.

\section{To Sir H. Davy, Barl. P.R.S. $\mathscr{G}^{\circ}$. $\quad$ Henry Kater.}

P.S. Since the preceding letter was written, I have ascertained that the spot in which I observed the volcanic appearance is that named Aristarchus. This spot was particularly examined by Hevelius, who calls it Mons Porphyrites, and who considers it to be voleanic. If his drawings are to be relied upon, it has undergone a considerable change in its appearance since his time.

Sir William Herschel has recorded in the Philosophical Transactions an observation of three volcanoes, which he perceived in the moon, April 19,1787 , at $10^{\mathrm{h}} 36^{\mathrm{m}}$, sidereal time. One of these, which he says showed " an actual eruption of fire or luminous matter," was distant fron the northern limb of the moon $3^{\prime} 57^{\prime \prime} \cdot 3$, the diameter of the burning part being not less than $3^{\prime \prime}$. I find that this observation was made about 9 o'clock in the evening, when the moon was not quite two days old; and from the situation of the spot described by Sir William Herschel, I have no doubt of its being the same that I have noticed.

XXVII. The first Portion of a Catalogue of 1800 zodiacal Stars, for the Epoch of January 1, 1800 ; from the Works of Prazzi, BoDk, and others, with illustrative Notes. Selected and arranged by a Member of the Astronomical Society of London.

I : the present and five following portions, it is intended to offer to the amateurs of Astronomy, a Catalogue of Stars lying within $10^{\circ}$ on either side of the Ecliptic ; arranged in the order of their passing the meridian, and coutaining not only the mean Right Ascensions and Declinations, but as many other accurate and useful particulars, as the compiler's materials, and the limits of an octavo page, will permit.

By referring to the notice inserted p. 394 of the preceding volume, it will be seen that a general catalogue of stars is announced, comprising in number about 4000 , and extending over that part of the heavens which is visible to British observers. This extent it was intended to divide into four districts, and the most natural arrangement would be to commence with that which is constantly above our horizon. The slow progress, however, which 